\title{
O FEMINISMO ISLÂMICO NA TRANSIÇÃO POLÍTICA DA TUNÍSIA: AVANÇOS E RETROCESSOS.
}

\author{
ISLAMIC FEMINISM IN TUNISIA'S POLITICAL \\ TRANSITION: ADVANCES AND SETBACKS.
}

\author{
Ana Gabriela Costa Reis ${ }^{1}$
}

\begin{abstract}
Resumo: Este trabalho busca investigar os indícios de avanços nos direitos das mulheres no pós Primavera Árabe da Tunísia, entre os anos de 2010 e 2014, através das categorias analíticas do feminismo islâmico e do pós-colonialismo. Em função da agitação político-social refletida nas grandes manifestações populares clamando por maiores liberdades, e evidenciando um hiato entre os direitos garantidos pelo texto constitucional existente no período precedente à Primavera Árabe, o de 1959, trabalha-se aqui com a hipótese de que essa oportunidade teria sido aproveitada pelas tunisianas, tendo sua luta simbolizada na nova constituição de 2014. Para tanto, observa-se os trechos constitucionais de 1959 e 2014 e avaliam-se os reflexos das lutas de gênero. Conclui-se que as mulheres obtiveram sucesso em sua luta, ao menos no sentido de terem sido garantidos, na nova constituição, seus direitos e deveres. Além disso, inferiu-se, a partir de seus ganhos, a confirmação de que o feminismo islâmico não deve ser compreendido sob a perspectiva ocidental, uma vez que cada movimento possui suas próprias reivindicações e particularidades.
\end{abstract}

Palavras-chave: Tunísia; Primavera Árabe; Feminismo Islâmico.
Abstract: This essay seeks to investigate the evidence of advances in women's rights in Tunisia in its postArab Spring (2010 - 2014), through the analytical categories of Islamic Feminism and Postcolonialism. Due to the political and social upheaval reflected in the popular manifestations calling for greater freedoms, and showing a gap between the rights guaranteed by the constitutional text existing at the time, it is hypothesized that this opportunity would have been seized by the women in Tunisia, which their fight is now symbolized in the 2014 constitution. Therefore, the constitutional stretches of 1959 and 2014 are observed, and the reflexes of gender struggles are evaluated. It is concluded that women were successful in their struggle, at least in the sense that their rights and duties were guaranteed in the new constitution. Furthermore, it was inferred, from their gains, the confirmation that Islamic feminism should not be understood from the Western perspective, since each movement has its own particular demands.

Keywords: Tunisia; Arab Spring; Islamic Feminism.

\section{Introdução}

A Tunísia como palco inaugurador da Primavera Árabe, iniciada em 2010, teve por objetivo depor o autocrata Zine El Abidine Ben Ali, em busca de melhorias nos aspectos sociais e garantia de direitos civis. Esse levante social obteve êxito em janeiro de 2011, culminando em uma reestruturação política que resultou na constituição promulgada em 2014. Nesse sentido, no estudo que se segue, investiga-se se tal reconfiguração política

\footnotetext{
1 Ana Gabriela Costa Reis é bacharela em Relações Internacionais pelo Centro Universitário Instituto de Educação Superior de Brasília - IESB. Tem interesse em temas relacionados ao Oriente Médio e estudos de gênero. ORCID ID: https://orcid.org/0000-0002-8291-2462. Link para o Currículo Lattes: http://lattes. cnpq.br/3216450137887300. E-mail para contato: anagabrielar7@gmail.com.
} 
alcançada se estende às mulheres da Tunísia, observando o feminismo islâmico e a perspectiva pós-colonial.

Nessa acepção, nesse ensaio discute-se quanto aos avanços e retrocessos da população de mulheres na Tunísia, país resignado ao Islã sunita. Trabalha-se, portanto, com a hipótese de que após a Primavera Árabe no país norte-africano, as mulheres obtiveram conquistas em termos sociais, as quais estão garantidas na constituição promulgada em 2014.

Para isto, utiliza-se do método de pesquisa descritivo bibliográfico, a fim de compreender o contexto social e político da Tunísia, e, ainda, do método comparativo e a análise documental das constituições de 1959 e 2014 para demonstrar resultados advindos das inquietações.

\section{O Islã, o Feminismo Islâmico e o Pós-colonialismo: da epistemologia à ontologia}

O Islã é a religião majoritária em todo o mundo árabe e acaba por definir valores e princípios que recaem sobre a estrutura social da região. A religião monoteísta surgiu em meados do século VII d.C., na Península Arábica, por meio de aparições e revelações ao mercador Muhammad. As instruções sagradas por ele recebidas foram materializadas no que se tornou o livro sagrado da religião, o Corão (Fernando Brancoli, 2014: 152).

Um dos conceitos que permeia a religião islâmica é o jihadismo. Embora deturpado na contemporaneidade, jihadismo significa atingir a fé sublime por meio das práticas religiosas do Islã, e jihad é aquele que a prática. Configurado em dois conceitos, o jihad nafs corresponde ao esforço de cada indivíduo para ser um muçulmano melhor; e o jihad como guerra (qital) representa o muçulmano que precisa resistir, por exemplo, às agressões e ao colonialismo (Francirosy Barbosa, 2016: online).

Dentre as dimensões existentes para se compreender o Islã, uma das mais importantes para a notoriedade que ele adquiriu no mundo é a política. Essa esfera política é caracterizada como fundamental para a religião e sua práxis, e adquire roupagem de uma política justa, que possui as respostas e saídas mais adequadas frente aos desafios enfrentados pela umma (comunidade de todos os adeptos ao Islã ao redor do mundo). A Xaria, assim denominada, é a interpretação legal do Corão e da Hadith, e essa interpretação pode variar de país a país, guiando todos os aspectos da vida muçulmana (Maria Jesús Mata, 1998: 20).

Ela é constituída por normas e leis que sustentam tanto a jurisprudência dos países muçulmanos quanto sua filosofia, e um dos aspectos mais facilmente observados na Xaria são o casamento e divórcio. Ela orienta, em sua maioria, o substrato constitucional dos países muçulmanos, havendo certas alterações a depender da interpretação islâmica adotada ${ }^{2}$ (Toni Johnson e Mohammed Aly Sergie, 2014: online).

O Islã é uma religião importante no cenário internacional, uma vez que, além de ter bilhões de adeptos, ele delineia toda a esfera político-social de muitos países no Oriente Médio e África, em razão da forte presença de seus preceitos. No entanto, até os anos 1980,

\footnotetext{
${ }^{2}$ A cargo de exemplificar, três das tradições islâmicas são o xiismo, sunismo e carijismo. Na Tunísia, a maioria da população é sunita.
} 
não era uma religião fortemente conhecida pelo Ocidente, o fato que alterou essa configuração foi a influência da minoria xiita do Islã, com a Revolução Iraniana em 1979, sob a liderança do Aiatolá Ruhollah Khomeini (John Esposito, 2002: 36).

A partir disso, foi instituído o fundamentalismo islâmico no Irã, em que o Islã passa a atuar dentro das estruturas estatais. Isso chamou a atenção de países ocidentais, uma vez que não queriam que esses ideais iranianos, bem como toda a sua movimentação, conquistassem os demais países muçulmanos, já que Khomeini implementa uma nova concepção de Estado islâmico autodeterminado, contrariando fortes interesses geopolíticos e geoeconômicos (Esposito, 2002: 36).

A vista desse panorama, o fundamentalismo islâmico, que se insere no mundo muçulmano como recusa ao que o Ocidente deseja incorporar às sociedades resignadas a essa religião, teve seu surgimento à época antecedente ao século XX, como reação à colonização ocidental (Peter Demant, 2018: 319). A exemplo, tem-se o Pan-arabismo, originado na Síria no final do século XIX, com a ideia de uma identidade árabe coletiva; o surgimento da Irmandade Muçulmana no Egito, em 1928; a fundação do Partido Baath, na Síria, em 1947; e a afirmação da República Islâmica do Irã, em 1979 (Demant, 2018: 95).

0 pan-arabismo defende a ideia de unidade regional, levando em consideração a língua, ancestralidade e as tradições associadas a ele. Havia divergências relacionadas aos limites desse nacionalismo, em que, para alguns, a economia, cultura e segurança eram os temas centrais e decisões acerca da soberania deveriam ser tomadas sob esses três pontos. Para outros, deveria ir além das fronteiras, com a ideia de extinção das fronteiras outrora estipuladas pelo colonialismo ocidental, para então chegar à noção de Estado Árabe Unido (Sílvia Ferabolli, 2007: 68).

Por conseguinte, fundamentalismo islâmico, comumente denominado "islamismo", nasce como reação à modernidade ocidental e sustenta a ideia da existência de um Estado islâmico. A modernidade, para a finalidade desse ensaio, assume a conceituação de que ela não é considerada uma proposta de emancipação social, mas o contrário: a dominação e exploração de civilizações (Ramon Grosfoguel, 2017: online). Ela declara, ainda, a ideia de que religião e política devem estar dissociadas, assim, caracterizando um Estado secular, que suprime a religião em detrimento de uma globalização. Os islamistas, por sua vez, consideram que a colonização significou o desaparecimento significativo do controle político, militar e ideológico muçulmano em sua própria sociedade, e é pontualmente em razão disso que se dá a resistência em relação à modernidade (Demant, 2018: 200).

Há subdivisões de objetivos dentro deste fundamentalismo, em que certos grupos defendem a criação de normas sociais religiosas, o que os leva a se concentrarem na reforma da conduta individual. Dessa forma, esses grupos podem estar mais alinhados a questões como segregação sexual, produção cultural e até mesmo à conduta moral. Os mais extremistas, por exemplo, consideram a utilização da violência como meio de conquistar seus ideais de domínio islâmico (Kecia Ali e Oliver Leaman, 2008: 41). 
Não obstante, o fundamentalismo inseriu um novo conceito de jihadismo e reinterpretou a concepção inicial que o profeta Muhammad havia proferido no Corão. 0 jihadismo, sob a perspectiva do islamismo, passa a significar Guerra Santa, motivada por interesses políticos, sendo os jihadistas aqueles que executam as práticas do jihadismo, que, em sua maioria, utilizam da violência para reafirmar o domínio ou estabelecer e/ou confirmar zonas de influência. Por conseguinte, os jihadistas acreditam que sacrificar suas vidas pelos ideais islâmicos é digno, uma vez que a finalidade é se alicerçar na sociedade, e, por isso, são perdoados por Allah (Ali e Leaman, 2008: 41).

Sendo assim, esse fundamentalismo se caracteriza por interpretar irrestritamente documentos sagrados como forma de justificar seus atos, e objetiva estabelecer uma ordem política islâmica e mudar sua sociedade nos moldes religiosos. 0 Estado ${ }^{3}$, portanto, é o foco dos fundamentalistas, já que ele é o núcleo da modernidade e de todos os eventos transnacionais (Jonathan Fox e Shmuel Sandler, 2004: 84).

Destarte, o fundamentalismo tem como finalidade desalinhar a ideia de separação entre entidades religiosas e governamentais, e sustenta-se a afirmativa de que se deve retornar à realidade social previamente existente, a qual nega costumes e hábitos importados, e tem como um de seus princípios regressar à Santa Lei do Islã, a Xaria (Bernard Lewis, 2002: 106).

0 apelo à religião, no entanto, não se restringe apenas ao retorno às leituras literais dos escritos religiosos, mas sustenta-se, ainda, no discurso de que os ensinamentos religiosos podem ser aplicados com eficácia à sociedade e vida política contemporânea. Nesse sentido, o fundamentalismo refere-se muito mais às práticas corretas da religião (ortopraxia), do que aos ensinamentos dela (ortodoxia) (Fred Halliday, 2005: 212).

Dito isso, parte-se às concepções acerca do feminismo islâmico e como ele está inserido no contexto do mundo muçulmano e do globo, como um todo. Esse movimento perpassou as barreiras do patriarcado muçulmano e adentrou nesse mundo apresentando às mulheres o poder da fala e do diálogo, a importância da realização de lutas e aquisição de direitos e liberdades. No entanto, o ativismo que existiu dos anos 20 aos 80 não abrangia a todas as mulheres ativistas muçulmanas. Assim, os feminismos seculares que existiam em países muçulmanos cederam lugar ao feminismo islâmico (este que se adequa à perspectiva religiosa), e como uma de suas enunciações, tem-se a contestação às interpretações fundamentalistas da Xaria, uma vez que ela tem impacto direto e negativo na vida das mulheres (Lila Abu-Lughod, 2013: 27).

O feminismo islâmico surgiu em países como o Egito, Turquia e Marrocos, estes que são os precursores do movimento. Em 1910 já era debatido quanto ao uso do véu por uma parcela de mulheres, especialmente nas terras egípcias, o que acabou por influenciar os demais países da região árabe, como a Tunísia (Leila Ahmed, 1992: 172).

\footnotetext{
3 Para os fundamentalistas, a criação de um Estado, que consequentemente permite inferir ser um Estado secular, vai contra seus ideais. O que seria equivalente ao Estado, para os fundamentalistas, seria o Califado, a forma de governo em que o califa tem atribuições de chefe político, religioso, militar e judicial.
} 
Isso posto, a década de 1990 é marcada por anunciar, oficialmente, o feminismo islâmico ao mundo, sobretudo com a marroquina Fatema Mernissi, esta que inspirou muitas feministas islâmicas com sua obra "Women and Islam: an Historical and Theological Enquiry" publicada em 1991 (Fatema Mernissi, apud Clarissa de Franco, 2016: 87). Assim, durante o século XX houve um aumento do ativismo de mulheres muçulmanas, e ele passa a ensejar o reconhecimento da importância do gênero na construção de uma sociedade mais justa e equitativa (Ahmed, 1992: 169).

De acordo com Aïcha El Hajjami (2008: 5), os princípios que instituíram as bases das relações sociais no Islã corroboram e sustentam esse movimento político-ideológico. Dentre eles, a autora destaca:

\footnotetext{
a igualdade dos seres humanos supõe a abolição de todo tipo de dominação ou de discriminação por sexo, raça, cor, riqueza ou classe, e cada ser humano é valorizado apenas por sua compaixão e boas ações;

a diversidade dos seres humanos é uma fonte de paz e de enriquecimento, geradora de respeito pelo outro e de não violência contra eles, uma vez que lhes é recomendado estabelecer reconhecimento mútuo, no sentido intelectual e espiritual do termo;

os seres humanos, enquanto representantes de Deus na terra, são iguais em sua responsabilidade pela vida na terra, o respeito pelas outras criaturas e a preservação do ambiente (Hajjami, 2008: 5).
}

Assim, esse feminismo que surge em paralelo às práticas fundamentalistas do Islã defende que há uma construção social e histórica de submissão das mulheres no mundo muçulmano, e que, tendo o islamismo como um dos principais motivadores já que ele obstaculiza a integração feminina na sociedade, passa-se a lutar por direitos equitativos e por liberdades (Haideh Moghissi, 2002: 130). As discussões tangentes ao feminismo islâmico nasceram inspiradas, em parte, na sociedade secular, em busca de equidade de gênero e liberdade de vestimenta. No entanto, esse feminismo contrapõe ao feminismo ocidental, visto que esse possuía à época, e possui até os dias atuais, características e premissas diferentes que não se enquadram à realidade das mulheres muçulmanas. Por contrapor ao feminismo de princípios seculares, isto é, aquele que contesta retóricas baseadas no discurso religioso, o feminismo islâmico acaba por ser colocado às margens pelo ocidente, não sendo legítimo de acordo com seus preceitos (Clarissa de Franco, 2016: 88).

Muitos movimentos feministas ao redor do mundo consideram a religião como o principal motivo para a existência da submissão das mulheres (Franco, 2016: 89). Contudo, a população de mulheres adepta ao Islã e ao feminismo islâmico recai sobre esse discurso afirmando que seu principal objetivo é a reinterpretação e releitura dos escritos religiosos, como Corão, Xaria e os ahadith e utilizam deles para reforçar que a religião não possui caráter patriarcal e opressor, mas que a problemática reside na cultura do preconceito que está enraizado e é responsável por colocar as mulheres muçulmanas sob situação de inferioridade (Amal Treacher, 2003: 64). A reinterpretação e releitura a qual elas se referem, 
baseiam-se nas premissas islâmicas de ijtihad (a interpretação dos juristas para produzir uma explicação racional das fontes religiosas islâmicas), da tafsir (explicação crítica sobre o Corão), os ahadith (histórias do profeta Muhammad), e a fiqh (jurisprudência do Islã) (Cila Lima, 2017: 89).

A reinterpretação dessas fontes sagradas se faz necessária uma vez que prescrições corânicas, por exemplo, foram deduzidas e tiveram seu significado simplificado. À época da Revelação, muitos ensinamentos e pautas eram presentes e promoviam a emancipação social, além de garantirem a igualdade (nos termos do Islã) para todos os indivíduos. Dentre as prescrições que foram deturpadas ao longo do tempo pelos intérpretes dos textos sagrados, estão os casos de poligamia, divórcio e herança, esses exemplos podem ser ressignificados a partir do ijtihad (Hajjami, 2008: 7).

Desse modo, o feminismo islâmico gera muitas discussões não apenas no Ocidente, mas, ainda, no próprio mundo muçulmano. Por ser oriundo de uma concepção ocidental, ele consequentemente possui uma conotação de transformação que não é facilmente encontrada no Islã, e que é refutada por grupos mais extremistas. Mas ainda que exista essa parcela da população muçulmana que não considere o feminismo como legítimo, há uma grande parte, composta especialmente pelas mulheres, que defende que o Islã não prega a ideia de submissão entre os gêneros (Ali e Leaman, 2008: 37).

Embora as interpretações do Corão determinem suas particularidades e o torne vasto em termos de multiplicidade analítica e formas de adoção da religião pela sociedade, o Ocidente tende a analisá-lo como uniforme e previsível. Contudo, o ideal não é observá-lo unicamente sob a lente ocidental e uniformizar suas ações, movimentações, cultura, costumes e política, e isso se estende ao feminismo islâmico, movimento em que há a existência de igual complexidade, em que cada sociedade busca, ao seu modo, garantias de equidade (Franco, 2016: 84).

Dessa forma, a abordagem pós-colonial, a qual objetiva pluralizar as concepções e expor que movimentos e maneiras de se pensar divergem em razão da natureza de cada sociedade e que isso não os invalida, surge após questionamentos advindos de países que outrora foram colônias europeias, os quais, sob a perspectiva conceitual, buscavam maneiras de mostrar que tais potências pressupunham sua inferioridade, impondo valores e costumes sobre tais países (Antônio Manoel Elíbio Jr., Carolina de Almeida e Marcos Costa Lima, 2013: 451).

Por conseguinte, como obra inspiradora do Pós-colonialismo, o Orientalismo, de Edward Said, inaugura a corrente teórica expondo críticas às agressivas colonizações europeias, as quais impactaram diretamente nos âmbitos geográfico, cultural e moral. Essas potências, de acordo com o Orientalismo, negavam a autonomia de suas colônias por considerá-las incapazes de se autodeterminar e governar (Edward Said, 2004: 19).

0 caráter de ator dominante sobre, principalmente, a região afro-asiática, reforça o que o Orientalismo introduz: que se conhece o outro através de suas próprias perspectivas, 
e não como ele realmente é, e, dessa forma, generaliza-se os atores. Dessa forma, o cenário mundial que surge em decorrência da descolonização afro-asiática dá margem aos estudiosos para investigarem mais a fundo os países daquela região, e o pós-colonialismo assume um feitio instrumental crucial para identificar as dinâmicas desses países que, até então, estiveram à margem dos pensamentos globais em razão da epistemologia eurocêntrica (Elíbio Jr., Almeida e Lima, 2013: 451).

Com o Orientalismo introduzindo a epistemologia de países do sul para os seus, a fim de pluralizar as concepções globais, seu propósito gira em torno de apresentar a heterogeneidade existente, e não a uniformidade, a qual define, molda e posiciona os sujeitos, como o Ocidente pressupõe. 0 escopo final, portanto, é emancipar a sociedade do discurso de que o Oriente é obsoleto, buscando nivelá-lo em relação ao Ocidente, rejeitando sua subjugação (Elíbio Jr., Almeida e Lima, 2013: 455).

Assim, o Pós-colonialismo que surge no século XX, tem a intenção de mostrar às Relações Internacionais que países que possuem ideias não-ocidentais têm suas epistemologias válidas da mesma forma que as elaboradas no Ocidente. 0 escopo dessa corrente teórica, portanto, reside em emancipar a academia no sentido epistêmico, e trazer interpretações, formas de conhecimento e vozes outrora hostilizadas. 0 Pós-colonialismo reforça, por fim, que cada região possui suas singularidades, e que elas devem ser respeitadas e não uniformizadas e tipificadas.

\section{A trajetória feminina na Tunísia nos períodos pré e pós-Revolução de Jasmim}

A Tunísia é um país que desde o início de sua história independente teve uma postura diferente de seus vizinhos regionais no que tange à garantia à participação e inclusão feminina na sociedade. Ao adotar premissas emancipatórias para as mulheres antes e durante o governo de Habib Bourguiba (este que foi Primeiro-Ministro do país no período de 1956 e 1957, e, em seguida, o primeiro presidente no período de 1957 a 1987), as reformas implementadas corroboraram com a busca por paridade de gênero.

A introdução do Código de Status Pessoal (CSP) de 1956 apresentou às mulheres um documento pautado na abolição da poligamia; garantia do direito de divórcio; idade mínima para o casamento de meninas; entre outros. A adoção desse documento fez com que o país já passasse a se configurar como distinto dos demais países muçulmanos (Mounira Charrad e Amina Zarrugh, 2014: 233).

Habib Bourguiba acreditava que para a Tunísia adquirir o caráter de sociedade emancipada e desenvolvida, era fundamental que todos tivessem as mesmas oportunidades e fossem iguais perante o Estado. Desenvolvendo uma nova fase da ijtihad, o governo passou a adotar a concepção de igualdade de oportunidade, e sustentada por organizações de mulheres, passou-se a surgir uma consciência feminista sem deixar os valores islâmicos, conforme Amel Grami (2008: 351) afirma: 
esse novo pensamento incluiu reformas para gerar igualdade de gênero nas áreas de casamento, divórcio, guarda dos filhos e autonomia social das mulheres. Os defensores das reformas não veem isso como um abandono dos valores islâmicos, mas como uma evolução para o período moderno (Grami, 2008: 351).

Entende-se, no entanto, que os direitos das mulheres na Tunísia podem ser considerados como motivação e produto do Estado. A exemplo, tem-se o CSP de 1956, que se deu por iniciativa de Habib Bourguiba. Essa realidade não foi alterada com a autocracia estabelecida por Zine El Abidine Ben Ali (1987-2011), em que, durante seu governo, os direitos e deveres das mulheres continuaram sendo garantidos, mas as mulheres não tinham suas reivindicações levadas em consideração. Nesse sentido, entende-se que os direitos das mulheres nesse país eram expressões da liderança estatal, e não da pressão social (Charrad e Zarrugh, 2014: 233).

Apesar disso, o regime de Ben Ali foi marcado pela proibição da liberdade de expressão dos cidadãos, e somada à concentração de poder, estes se tornaram os maiores empecilhos para avançar em temas sociais cruciais para o desenvolvimento do país, como maior busca e garantia de paridade de gênero no âmbito sociopolítico. 0 controle estatal se estendia às associações de mulheres, e ativistas passaram a ser perseguidas e censuradas (Charrad e Zarrugh, 2014: 233).

Essa realidade a qual as mulheres estavam inseridas perdurou até o desponte da Revolução de Jasmim (assim denominada a Primavera Árabe tunisiana, que ocorreu de dezembro de 2010 a janeiro de 2011), e o período de repressão que vigorou no governo de Ben Ali funcionou como motor para que as mulheres unificassem sua luta e deixassem de lado a tônica excludente, elitista e racista que existia dentro do próprio gênero, e buscassem, por meio da pressão social, equidade de gênero (Janna Kadri, 2018: 15). As manifestações ocorridas na Tunísia foram noticiadas e tiveram grande repercussão através dos meios de comunicação, o que fez com que se espalhasse por todo o mundo e inspirasse uma movimentação social dentro dos países da região que se encontravam em situação similar à tunisiana (Fernando Brancoli, 2013: 54).

A participação das mulheres na Primavera Árabe tunisiana, de início, não apresentava uma ideologia específica e elas não faziam parte de nenhuma associação (como sindicatos) ou organização política para protestar e rogar por pautas específicas. A ideia inicial, portanto, era a deposição de um regime que falhou com a sociedade no sentido socioeconômico. Nessa conjuntura, as mulheres perceberam que o processo revolucionário as ajudaria a lutar pelos seus direitos, e que o levante poderia ser utilizado a seu favor para mudar a realidade de repressão que viviam, e, como consequência, sair da margem social (Kadri, 2018: 16).

A Revolução de Jasmim possibilitou que as mulheres expusessem, em sua totalidade, suas insatisfações e lutassem por seus direitos, e principalmente que esses englobassem e se estendessem às mulheres desfavorecidas, fora de Túnis. 0 debate público e a expressão 
de suas opiniões sem censura foram experimentados por essas mulheres, e sua ampla participação e organização de protestos incluíram com persistência a ideia de equidade de gênero, que adentrou a sociedade tunisiana de uma forma inexistente até então (Charrad e Zarrugh, 2014: 233).

O período mais intenso de manifestações na Tunísia terminou em janeiro de 2011, e com ele o sucesso materializado na deposição e exílio de Zine El Abidine Ben Ali. Assim, o país inicia de pronto a sua reestruturação política, estabelecendo uma Assembleia Constituinte. 0 principal objetivo, portanto, era originar uma nova constituição, de modo a reorganizar o funcionamento do Estado; a busca por transparência governamental (esta que era um dos grandes problemas do governo de Ben Ali); representação política; assim como a garantia de direitos e deveres dos cidadãos que anteriormente foram violados (Amira Aleya-Sghaier, 2012: 26).

Nessa conjuntura de transformação sociopolítica, as mulheres também buscaram fazer parte da elaboração da nova Carta Magna que regeria o país, para que fosse garantida a equidade de gênero, mas, desta vez, de acordo com suas necessidades, e não como nas administrações de Habib Bourguiba e Zine El Abidine Ben Ali, em que os direitos e políticas públicas partiam do próprio Estado (Charrad e Zarrugh, 2014: 233).

Para garantir a paridade de gênero na representação, foi estabelecida, a partir de um conjunto de mulheres/ feministas islâmicas, o projeto de lei eleitoral realizado por um comitê de especialistas de organizações de mulheres, como a Associação Tunisiana de Mulheres Democráticas (ATFD) ${ }^{4}$, e a Associação Tunisiana de Mulheres para Pesquisa e Desenvolvimento (ATMPD) $)^{5}$. A lei eleitoral exigia que houvesse a participação de mulheres na lista eleitoral, para que, dessa forma, os direitos e deveres fossem garantidos às mulheres na nova constituição. Desse modo, isso se configura como uma forma de se buscar, ainda, a representatividade (Charrad e Zarrugh, 2014: 234).

Seguindo a formalidade dessa lei eleitoral, o Al-Nahda, partido islâmico que obteve maior sucesso nas eleições para formar a Assembleia Constituinte, contava com mulheres o compondo, e, por conseguinte, a representatividade feminina fora incluída, em que quarenta e duas (42) mulheres estavam afiliadas a esse partido. No total, dos 217 deputados na Assembleia Nacional Constituinte, 49 eram mulheres, e dos 101 membros das Comissões Parlamentares, 28 eram mulheres (Duncan Pickard, 2013: 640).

O Al-Nahda, no entanto, começou a despertar questionamentos acerca da sua influência nos direitos das mulheres na Tunísia quando tentou introduzir leis mais rígidas que pressupunham uma inclinação ao fundamentalismo na confecção da constituição. A proposta do Al-Nahda quanto ao artigo 28 no rascunho da nova constituição gerou discussões dentro da Assembleia Constituinte, e novas manifestações eclodiram nas ruas tunisianas. 0 artigo propunha que as mulheres fossem colocadas como complementares aos homens, e, com

\footnotetext{
4 Association tunisienne des femmes démocrates.

${ }_{5}$ Association des femmes tunisiennes pour la recherche et le développement.
} 
isso, as relações sociais entre mulheres e homens seriam afetadas, e não apenas no aspecto matrimonial, mas social como um todo (Charrad e Zarrugh, 2014: 235).

0 debate incitou protestos e promoveu petições quanto à utilização dos termos "igual" ou "complementar" para confeccionar o artigo. Os defensores dos direitos das mulheres, associações feministas, e a sociedade civil argumentavam sobre a necessidade e importância de se colocar o termo "igual", porque, dessa forma, toda a luta feminina ao longo de anos, não seria arruinada pela proposta do partido islâmico. Por fim, as discussões e protestos culminaram em êxito para a população de mulheres, que conseguiu que o termo sinônimo de igualdade fosse levado em consideração, e representava, de fato, a vontade do povo, e não apenas do partido (Charrad e Zarrugh, 2014: 236).

Nesse seguimento, as discussões acerca da estruturação da Carta Magna persistiram, até que, por fim, foi promulgada a nova constituição da Tunísia em 2014. Este novo documento apresentou ideias diferentes da precedente realidade tunisiana, garantindo direitos e deveres aos cidadãos, e, assim, atendendo às demandas sociais que foram expostas de dezembro de 2010 até a finalização do novo texto constitucional. (Alexis Arieff, 2011: 3).

Além disso, a constituição de 2014 retrata, ainda, um ganho às tunisianas, que agora dispõem do gozo de direitos e deveres alinhados às suas necessidades, estando prescritos constitucionalmente. Essa nova carta magna configurou que a luta das mulheres, apoiada por associações, ativistas e feministas islâmicas, e demais grupos desde dezembro de 2010, foi fundamental para a elaboração desse documento que agora busca assegurar a paridade de gênero (Constituição da Tunísia, 2014).

\section{As Constituições da República da Tunísia de 1959 e 2014: interpretação e análise dos direitos das mulheres}

As constituições da República da Tunísia, tanto a de 1959, quanto a de 2014, despontaram em momentos cruciais, representando uma transição significativa no curso da história política e social do país. Em 1959, sob o cenário de independência da França, o país promulgou sua constituição em junho daquele ano, marcando a ruptura de protetorado francês para país independente. Já a constituição promulgada em janeiro de 2014, simboliza o reflexo das lutas sociais na denominada Revolução de Jasmim, parte do fenômeno Primavera Árabe.

As lutas femininas, embora não fossem o foco principal de toda a sociedade tunisiana na Primavera Árabe, contaram com a participação de uma quantidade significativa de mulheres, organizações e adeptos à causa indo às ruas, insatisfeitos com a então situação do gênero na sociedade, e buscaram maior representatividade, liberdade, garantia de direitos e deveres, além de equidade.

Nesse sentido, sob efeito de compreender se a constituição de 2014 contribui para afirmação da existência das lutas de gênero, estas consequentes do feminismo islâmico e 
todo o seu ativismo, na tabela abaixo aponta-se a incidência de termos análogos à mulher nesse novo texto constitucional, como um meio metodológico para corroborar com afirmações teóricas. Contabilizou-se e comparou-se a incidência de termos análogos à mulher nos textos constitucionais de 1959 e 2014, a fim de atestar se as mulheres adquiriram direitos e deveres, e consequentemente, se esse feminismo islâmico foi atingido dentro desta extensão metodológica. Os termos escolhidos para análise foram: mulher/mulheres; feminino; ela; dela/sua; gênero ${ }^{6}$.

Tabela 1 - Número de incidência nas constituições da República da Tunísia de 1959 e 2014

\begin{tabular}{|c|c|c|}
\hline Termos & $\begin{array}{c}\text { Quantidade de vezes citada } \\
(\mathbf{1 9 5 9 )}\end{array}$ & $\begin{array}{c}\text { Quantidade de vezes citada } \\
\text { (2014) }\end{array}$ \\
\hline Mulher/Mulheres & 0 & 6 \\
\hline Feminino & 0 & 5 \\
\hline Ela & 0 & 12 \\
\hline Dela/Sua & 0 & 13 \\
\hline Gênero & 0 & 1 \\
\hline
\end{tabular}

Fonte: Elaboração própria, com base nas constituições da Tunísia de 1959 e 2014. Junho de 2019.

A comparação entre as duas constituições torna-se pertinente para os fins desse ensaio, de modo que ela permite embasar o argumento de que houve a existência da luta feminina e, além de tudo, de que ela foi frutífera no período de 2010 a 2014, sendo essa consideração perceptível a partir do constante aparecimento de termos que não apareciam na antiga carta constitucional.

Nesse sentido, após o levantamento de dados e análise das constituições da Tunísia, artigos do texto constitucional de 2014 e a imperativa incidência de termos análogos à mulher permitem perceber a existência da luta das mulheres durante e após a Primavera Árabe. Tais conquistas se dão em razão da mudança de pensamento da sociedade e a prioridade que a pauta feminina adquiriu desde a entrada em vigor da constituição de 1959.

A conjuntura da época pós-independência que pode ter possibilitado a falta de incidência dos termos na constituição foi a prevalência do desejo da fundação de um Estado independente, que até então era protetorado francês, e pretendia definir o arquétipo governamental, e normas e direitos a serem seguidos pelos cidadãos. Por conseguinte, a Tunísia ansiava pelo reconhecimento da fundação de seu país por parte dos demais Estados no sistema internacional, com seus atributos de independência e soberania, apontando sua sociedade como politicamente organizada.

Ainda que o governo de Habib Bourguiba tivesse princípios de inclusão social das mulheres, os seus direitos não se mostraram explícitos no documento constitucional do país, e a aparição constante do advérbio de totalidade na constituição de 1959 não foi suficiente para sustentar e prescrever à população tunisiana que as mulheres deveriam

\footnotetext{
${ }^{6}$ As constituições observadas encontram-se no idioma inglês, e para tornar o texto mais dinâmico e cognoscível, traduziu-se os termos para o português.
} 
deter das mesmas prerrogativas que os homens tanto no governo de Bourguiba, quanto no de Zine El Abidine Ben Ali.

0 ano de 2010, portanto, foi crucial para as mulheres, em que elas aproveitaram das manifestações contra a autocracia para também expor suas insatisfações. Desse modo, esse fenômeno que foi aproveitado pelas tunisianas culminou em resultados explícitos para a população feminina, a partir da constituição de 2014, conforme aponta a Tabela 1. Com essa notável mudança de uma constituição para outra, e como consequência da maior incidência dos termos análogos à mulher, o novo texto constitucional, além de se mostrar mais completo, inclusivo, e demonstrativo, apresenta aos seus cidadãos, singularmente às mulheres, artigos que garantem direitos, liberdades civis, e equidade entre os gêneros.

Especialmente nos artigos 21, 34, 40, 46, 54 e 74 da constituição da Tunísia de 2014, é possível notar com maior transparência o reflexo das lutas de gênero no país do Magrebe. Isso posto, o Artigo 21 trata sobre todos os cidadãos, homens e mulheres, terem direitos e deveres iguais, e garante que todos são iguais perante a lei, sem qualquer discriminação (Tunisia, 2014, tradução da autora).

0 Artigo 34 discute a despeito dos direitos de eleição, voto e candidatura, e que eles são garantidos a todos os cidadãos. Além disso, passa-se a afirmar que o Estado tunisiano buscará garantir a representação de mulheres nos órgãos eleitos (Tunisia, 2014, tradução da autora).

No Artigo 40 é concedido o direito ao trabalho a homens e mulheres, e garante-se que o Estado tomará medidas necessárias para garantir o trabalho com base na competência e na equidade, e nesse mesmo artigo é abordado quanto ao salário justo para homens e mulheres. Já no que se refere ao Artigo 46, aborda-se sobre o comprometimento do Estado em proteger os direitos acumulados das mulheres, e que ele trabalhará com afinco para fortalecer e desenvolver esses direitos (Tunisia, 2014, tradução da autora).

Nesse sentido, após o Artigo 46 afirmar o comprometimento estatal para fortalecer direitos e deveres, os Artigos 54 e 74 passam a conferir direitos eleitorais e políticos tanto aos homens, quanto às mulheres. Confere-se, portanto, a todo cidadão tunisiano, a partir da idade de dezoito anos, o direito de voto, de acordo com as condições estabelecidas pela lei eleitoral. E, ainda, é garantido a todos os eleitores do sexo masculino e feminino que possuam nacionalidade tunisiana desde o nascimento, cuja religião seja o Islã, o direito de concorrer à eleição para o cargo de Presidente da República (Tunisia, 2014, tradução da autora).

Dessa forma, ao perceber a carência de artigos que garantissem e especificassem a equidade de direitos, deveres e liberdades às mulheres na constituição de 1959, e perceber que há não apenas menção a termos femininos na nova constituição, mas uma certificação neste substrato constitucional, depreende-se que a pauta de gênero não apenas entrou no debate sociopolítico do país muçulmano, mas que ele conseguiu atingir níveis parlamentares e mostrou à Assembleia Constituinte, responsável pela confecção da nova constituição, que 
a equidade de gênero deveria ser garantida, para que, assim, não houvesse lacunas para legitimar a misoginia e machismo.

Na Tunísia, portanto, as mulheres que até então não tinham seus direitos especificados na antiga constituição, passaram a tê-los detalhados nesta nova. Nesse sentido, essa constituição promulgada após a Primavera Árabe tunisiana demonstra que o feminismo islâmico se fez presente e real, indicando não haver incompatibilidade entre a religião e a garantia de direitos às mulheres. Essas conquistas denotam, desse modo, que a luta do gênero feminino foi próspera, mas cabe expor, ainda, o papel que a religião islâmica tem nesse país.

Muito embora o Islã seja considerado basilar para explicar condutas, atitudes e costumes no país norte-africano (como as bases alimentares), em outras esferas a religião não apenas explica a condição de suas mulheres nesse corpo social, mas mostra que é possível se inspirar em movimentos emancipatórios ao redor do globo, adequá-los ao seu contexto, e originar novos, os quais se enquadrem à realidade das mulheres. Isto é, o conceito de universalidade proposto pelo Ocidente não cabe a esse contexto tunisiano, e aponta-se que é possível adaptar o que ele propõe, sendo nesse caso, o feminismo.

Em alguns países muçulmanos é dado como comum a resignação ao fundamentalismo religioso, uma vez que utilizam do argumento de que a adoção do islamismo existe para preservar o país dos valores ocidentais e manter sua autodeterminação e escolha de seguimento religioso, político, e econômico. Assim, a Tunísia com atitudes e ações contrárias à adoção de um único princípio, aparenta buscar aliar ambas as ideias. Dessa forma, fator que contribui para a convergência entre o Islã e o ativismo feminino na sociedade tunisiana, é que a Tunísia não adota a Xaria como norteadora principal daquilo que rege o país.

Nota-se que o fato de ser um país que adota a práxis do Islã de forma mais branda em relação a outros países, e de modo não intransigente, o torna um Estado mais adepto a dinâmicas híbridas, de encontro entre princípios religiosos do Islã e proposições emancipatórias para as minorias. Assim sendo, a população feminina na Tunísia acaba por ter mais voz nesse país que em regiões mais fundamentalistas, como o Irã e Arábia Saudita.

A partir disso, a discussão acerca do binário se faz necessária. Dividir o globo entre Ocidente e Oriente, com o pressuposto de que um é válido e o outro não, torna-se um problema, uma vez que categorizar acontecimentos em apenas dois aspectos, e que esses dois aspectos são necessariamente opostos, cria um embate de validação. Nesse componente, encaixam-se os tipos de feminismo.

Conforme elaborado na Tabela 1, e de acordo com os artigos da constituição que asseguram a garantia de direitos às mulheres, o feminismo islâmico se mostrou forte e resistente em sua luta no contexto tunisiano. Assim, a partir da confirmação da primeira tabela e interpretação do texto constitucional, juntamente à discussão anterior sobre a participação feminina nessa sociedade, mostra-se que a refutação do feminismo secular é infundada.

Os objetivos de cada movimento são diferentes, considerando que cada localidade possui suas particularidades, singularidades e, também em razão da própria cultura, o 
argumento do feminismo ocidental não cabe à Tunísia. Aponta-se que a interpelação proferida pelo Ocidente, com um discurso colonialista, dificulta a própria inserção de mulheres muçulmanas no contexto nacional e mundial, já que defender padrões universais de equidade de gênero é problemático a partir do momento em que a diferença racial, posição de classe, localização geográfica e a cultura, moldam as experiências do gênero.

Dessa forma, as conquistas adquiridas pelas mulheres tunisianas apontam que sua cultura, a qual leva em consideração a presença do Islã, possui uma essência de compartilhamento de sentidos e significados para elas. Portanto, a Tunísia possui sua própria identidade, forma de pensar e interpretar situações, e que cabe às mulheres desse mesmo país identificarem suas respectivas necessidades, lacunas sociais e anseios.

A proposta da hermenêutica sob a ótica feminina muçulmana, por conseguinte, é válida. Ela se torna categórica justamente porque nos tempos do profeta Muhammad, afirmava-se que não deveria haver distinção de gênero, o que corrobora com a suposição levantada pelas mulheres de que foi uma cultura misógina socialmente construída, em busca de poder e supremacia. Assim, já que a releitura e reinterpretação dos textos sagrados busca a liberdade das mulheres e sua emancipação enquanto indivíduos, sua luta e movimento feminino tornam-se não apenas necessários, mas legítimos.

Por conseguinte, dentro dos limites da proposta metodológica, os desafios das mulheres foram deduzidos. No entanto, as lacunas deixadas pela metodologia utilizada recaem sobre a questão de quem está fazendo a política e para quem ela está sendo feita, no sentido de se as mulheres estão sendo representadas pelo seu gênero no parlamento, uma vez que a composição das cadeiras no congresso infere dizer que a busca por inclusão dessas mulheres na sociedade, persiste. Desse modo, entende-se as extensões do método utilizado, sendo possível conferir que houve indícios de avanços partindo da análise documental, e a partir dela é possível sugerir que novos avanços em termos de emancipação feminina podem surgir nessa sociedade.

Por fim, os direitos alcançados por essas mulheres reforçam a noção de que as lutas e movimentos político-ideológicos são necessários para a construção de uma sociedade menos segregada e com garantia de oportunidades a todos, ensejando o entendimento de que a conjuntura em que indivíduos marginalizados socialmente se encontram, pode ser alterada. Esse aspecto é fundamental para formulação de políticas eficazes em um país, no sentido de a luta ter partido de uma minoria populacional, que não dispunha da prática de seus direitos ou suas garantias, constitucionalmente. Desse modo, tudo isso transforma a percepção de que protestos e revoluções podem, de fato, significar mudança.

\section{Considerações Finais}

Ao longo do desenvolvimento do estudo foi possível compreender, a partir da análise das constituições da República da Tunísia de 1959 e 2014, que o feminismo islâmico 
não deve ser compreendido sob as lentes ocidentais, visto sua heterogeneidade e complexidade, e que, ao invés disso, é necessário analisá-lo considerando suas limitações e diferenças. Fundamentado nisso, passa-se a legitimar a existência de fenômenos e movimentos particulares de cada sociedade, e não a priorizar e enviesar interpretações.

Foi possível comprovar, ainda, que o Islã não é uma religião que se contrapõe à equidade de gênero e liberdades civis, mas que é a cultura do preconceito existente que obstaculiza suas garantias às mulheres. Assim, para as Relações Internacionais, o movimento feminino nas sociedades islâmicas se mostra fundamental, uma vez que atingir níveis de indiscriminação é um passo significativo para adquirir caráter de sociedade emancipada.

Em síntese, a hipótese levantada no início da pesquisa se fez verdadeira, e após a Primavera Árabe ocorrida na Tunísia entre 2010 e 2011, com a entrada em vigor da nova constituição em 2014, as mulheres obtiveram conquistas em termos sociais e políticos, as quais estão garantidas no texto constitucional.

Entende-se, por fim, que a busca por equidade de gênero situa-se na primeira categoria da luta feminina, e, após isso ser adquirido, as reivindicações das mulheres passam a ser outras. Dessa forma, o escopo das requisições muda de nível de acordo com o que fora conquistado anteriormente. Com base nisso, o estudo desperta uma nova problemática para a questão feminina na sociedade tunisiana: embora agora estejam garantidos direitos e deveres às mulheres no substrato constitucional do país, de que forma é possível certificar que as transformações nas relações sociais de fato existem, de acordo com o que consta nos artigos da nova constituição?

\section{Referências}

ABU-LUGHOD, Lila. Do muslim women need saving?. Massachusetts: Harvard University Press, 2013.

AHMED, Leila. Women and gender in Islam. 2 ed. New Haven: Yale University Press, 1992. ALEYA-SGHAIER, Amira. The Tunisian Revolution: The Revolution of Dignity. The Journal of the Middle East and Africa, v. 3, n. 1, p. 18-45, 2012.

ALI, Kecia; LEAMAN, Oliver. Islam: The Key Concepts. Routledge: Londres e Nova Iorque, 2008. ARIEFF, Alexis. Political transition in Tunisia. Congressional Research Service, abr. 2011.

BARBOSA, Francirosy Campos. Jihadistas são todos muçulmanos. Disponível em: https:// icarabe.org/politica-e-sociedade/jihadistas-sao-todos-muculmanos. Acesso em: 20 de abril de 2020.

BRANCOLI, Fernando. Islã Político, Direitos Humanos e Democracia: rearticulações e possibilidades. Monções, v. 3, n. 6, p. 149-168, 2014. 
BRANCOLI, Fernando. Primavera Árabe: praças, ruas e revoltas. São Paulo: Desatino, 2013. CHARRAD, Mounira; ZARRUGH, Amina. Equal or complementary? Women in the new Tunisian Constitution after the Arab Spring. The Journal of North African Studies, v. 19, n. 2, p. 230-243, 2014.

DEMANT, Peter. $O$ mundo muçulmano. 3 ed. São Paulo: Contexto, 2018.

ELÍBIO JR, Antônio Manoel; ALMEIDA, Carolina Soccio Di Manno de; LIMA, Marcos Costa. Edward Said e o Pós-Colonialismo. SÆculum - Revista de História, v. 29. João Pessoa, 2013. ESPOSITO, John. Unholy war: terror in the name of Islam. New York: Oxford University Press, 2002.

FERABOLLI, Silvia. Relações Internacionais do Mundo Árabe (1954 - 2004): os desafios para a realização da utopia pan-arabista. Contexto Internacional, Rio de Janeiro, v. 29, n. 1, p. 63-97, 2007.

FOX, Jonathan; SANDLER, Shmuel. Bringing Religion into International Relations. New York: Palgrave MacMillan, 2004.

FRANCO, Clarissa de. Feminismo Islâmico face ao feminismo secular: uma nova consciência de gênero de um Oriente que rejeita a Ocidentalização. Revista Último Andar, n. 26, pp. 84-92, 2016.

GRAMI, Amel. Gender equality in Tunisia. British Journal of Middle Eastern Studies, v. 35, n. 3, p. 349-361, 2008.

GROSFOGUEL, Ramon. 1492 and the Formation of Modernity. Islamic Human Rights Commission. Disponível em: https://www.ihrc.org.uk/publications/briefings/11878-1492-andthe-formation-of-modernity/. Acesso em: 15 de abril de 2020.

HAJJAMI, Aïcha El. A condição das mulheres no Islã: a questão da igualdade. Cadernos Pagu, v. 30, p. 107-120, 2008.

HALLIDAY, Fred. The Middle East in International Relations: Power, Politics and Ideology. New York: Cambridge University Press, 2005.

JOHNSON, Toni; SERGIE, Mohammed Aly. Islam: governing under Sharia. Council on Foreign Relations. Disponível em: https://css.ethz.ch/en/services/digital-library/publications/ publication.html/182296. Acesso em 10 de junho de 2020.

KADRI, Janna. Contribution des femmes à la construction de la nation, au processus révolutionnaire et au processus transitionnel en Tunisie. Université d'Ottawa, pp. 1-41, 2018.

LEWIS, Bernard. What went wrong?: Western impact and Middle Eastern response. New York: Oxford University Press, pp. 1-180, 2002.

LIMA, Cila. Feminismo islâmico: mediações discursivas e limites práticos. Tese de doutorado para o Programa de História Social, Faculdade de Filosofia, Letras e Ciências HUmanas, Universidade de São Paulo, 2017. 
MAKDISI, Samir. Reflections on the Arab Uprisings. Combining Economic and Political Development: The Experience of MENA. International Development Policy series 7. Geneva: Graduate Institute Publication, Boston: Brill-Nijhoff. Pp. 22-40, 2017.MATA, Maria Jesús Rubiera. La mujer en el Corán como fuente de la Xaria: posibilidad de nuevas interpretaciones. Aneles de Historia Contemporánea, 1998.

MOGHISSI, Haideh. Feminism and Islamic Fundamentalism: the limits of postmodern analysis. London \& New York: Zed Books, 2002.

PICKARD, Duncan. Challenges to legitimate governance in post-revolution Tunisia. The Journal of North Africa, v. 16, n.4, p. 637-652, 2011.

SAID, Edward W. Orientalismo: O Oriente como invenção do Ocidente. São Paulo: Companhia das Letras, 2004.

TREACHER, Amal. Reading the Other: women, feminism, and Islam. Journal of Studies in Gender and Sexuality, v. 4, n.1, pp. 59-71, 2003.

TUNISIA. Constitution (1959). Constitution of Tunisia. Tunis, Tunisia: Constituent Assembly, jun. 1959.

TUNISIA. Constitution (2014). Constitution of Tunisia. Tunis, Tunisia: Constituent Assembly, jan. 2014. 
